\title{
1 Boron evaporation in thermally-driven seawater desalination: Effect of temperature and operating conditions
}

\author{
A. Alpatova, A. Alsaadi, N. Ghaffour*
}

King Abdullah University of Science and Technology (KAUST), Water Desalination and Reuse Center (WDRC), Biological and Environmental Science \& Engineering (BESE), Thuwal 23955-6900, Saudi Arabia

*Corresponding author: noreddine.ghaffour@kaust.edu.sa

\section{Appendices}

Reagents: Analytical grade $\mathrm{H}_{3} \mathrm{BO}_{3}$, sodium hydroxide $(\mathrm{NaOH})$, nitric acid $\left(\mathrm{HNO}_{3}\right)$ and $\mathrm{UCON}^{\mathrm{TM}}$ THF 14 heating bath oil were purchased from Sigma-Aldrich (St. Louis, MO, USA). The Milli-Q water was generated by a Milli-Q Ultrapure Water System (Millipore Corp., Bedford, MA, USA). Red Sea water was collected from the sea intake pipe.

Glassware cleaning: All the glass parts of the Rotovapor ${ }^{\circledR}$ system were soaked in $1 \mathrm{M} \mathrm{HNO}_{3}$ for 30 min followed by rinsing with Milli-Q water and air-drying to prevent any cross-contamination of distillate samples from boron which might remain on the glass walls from the previous evaporation experiments. To ensure that boron was not leaching from the glassware, two additional tests were performed. In the first test, all glassware parts were soaked individually in the Milli-Q water for $72 \mathrm{~h}$, and boron concentration in this water was measured by the Inductively Coupled Plasma Mass Spectrometer (ICP-MS). In the second test, Milli-Q water was evaporated in the Rotovapor ${ }^{\circledR}$ system at the highest evaporation temperature of $104{ }^{\circ} \mathrm{C}$. Distillate water was further collected and analyzed for boron content. No boron was detected in any sample from both tests confirming no boron leaching from the glassware. Therefore, it was assumed that all the boron measured in the actual distillate water samples, has originated from the evaporation of seawater or boric acid solution.

Bench-scale evaporation experiments: The vapor duct and evaporating flask were connected through a $15 \mathrm{~cm}$ glass connector filled with a stainless steel demister to prevent carry over of droplets. A $500 \mathrm{~mL}$ round bottom evaporating flask was filled with $255 \mathrm{~g}$ of seawater or boric acid solution. The boiling temperatures were monitored with the mercury-in-glass thermometer immersed in the flask through the hole in neoprene rubber stopper. 
33 The detection limit of boron was $0.1 \mu \mathrm{g} / \mathrm{L}$ and the calibration curve was linear in the range of 1

$34 \mu \mathrm{g} / \mathrm{L}-100 \mu \mathrm{g} / \mathrm{L}$ with the coefficients of regression $\mathrm{R}^{2}$ being $>0.99$ during the entire period of measurements.

Virgin membrane conditioning: The AGMD process with Milli-Q water was conducted for $1 \mathrm{~h}$ at $70^{\circ} \mathrm{C}$ to wash out the residual solvents originated from membrane casting process. A new membrane coupon was used for each AGMD run.

The effect of feed temperature on vapor flux and boron rejection in the temperaturedependent AGMD process: The effect of feed temperature on water vapor flux and boron rejection in the AGMD process was studied in a feed temperature range of $65^{\circ} \mathrm{C}-80^{\circ} \mathrm{C}$ and at a

44 constant coolant temperature of $18^{\circ} \mathrm{C}$. The volume of the feed was $8 \mathrm{~L}$. A weight of permeate

45 which accumulated for one hour at each feed temperature was recorded and further used to 46 calculate the AGMD vapor flux according to equation A.2.

AGMD concentrating mode conditions: The initial volume of the feed in both cases was 4.125 temperatures, respectively, to maximize water vapor flux.

\section{Calculations:}

53 (1) The in situ $\mathrm{pH}$ values at different boiling temperatures were calculated according to the following equation:

55

$$
p H\left(\text { in situ temp } t_{2}\right)=p H_{t_{1}}+0.0114\left(t_{1}-t_{2}\right)
$$

56

57 where $t_{1}$ and $t_{2}$ are the ambient and in situ solution temperatures, respectively [29].

(2) The water vapor flux $(J)$ and boron rejection $(R)$ were calculated according to equations 
$62 J=\frac{m_{W}}{A t}$

63

$64 \quad R=\left(1-\frac{C_{p}}{C_{f}}\right) 100$

65

66 where $m_{W}$ is the permeate weight $(\mathrm{kg}), A$ is the membrane surface area $\left(m^{2}\right), t$ is the time (h),

$67 C_{p}$ is the concentration of boron in permeate $(\mathrm{mg} / \mathrm{L})$, and $C_{f}$ is the concentration of boron in feed $68(\mathrm{mg} / \mathrm{L})$.

69

70

71

72

73

74

75

76

77

78

79

80

81

82

83

84

85

86

87

88

89

90

91 


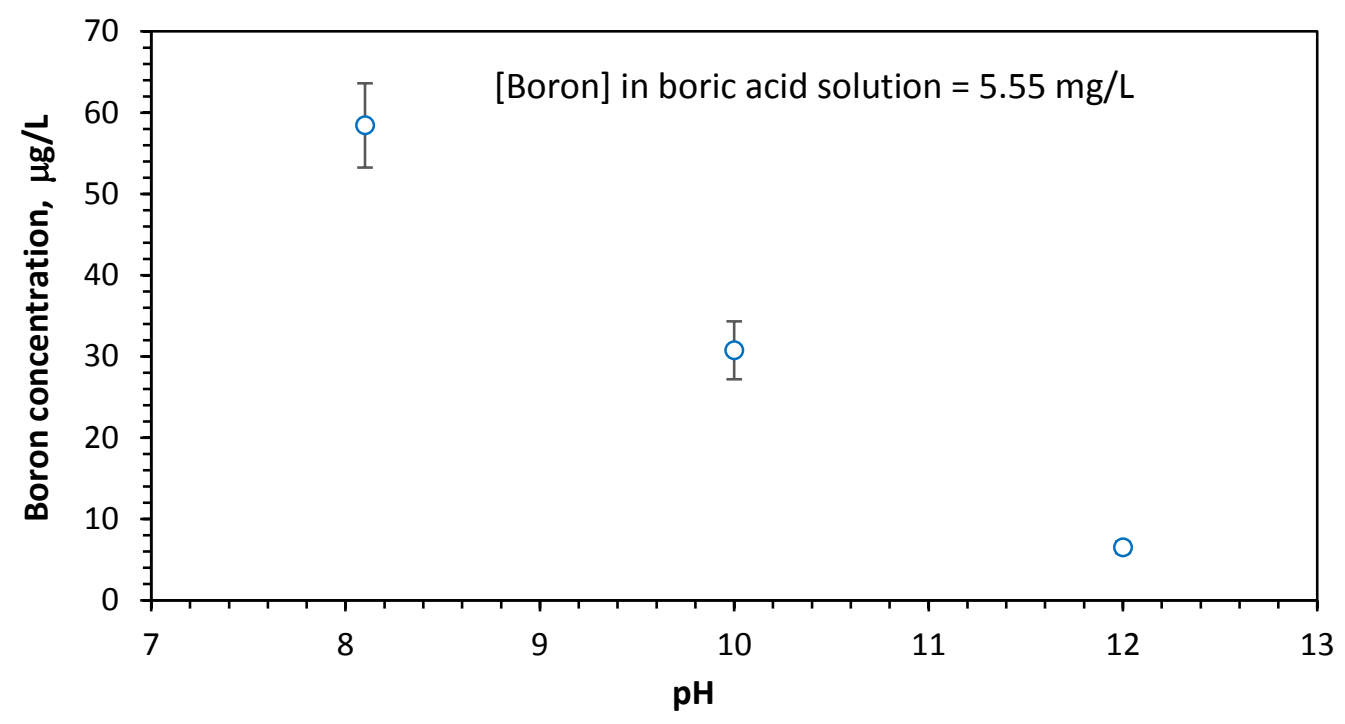

93 Figure A.1. Boron concentration in distillate samples from evaporation of boric acid solution at 94 $104{ }^{\circ} \mathrm{C}$ at different $\mathrm{pHs}$.

95

96

99 100 101

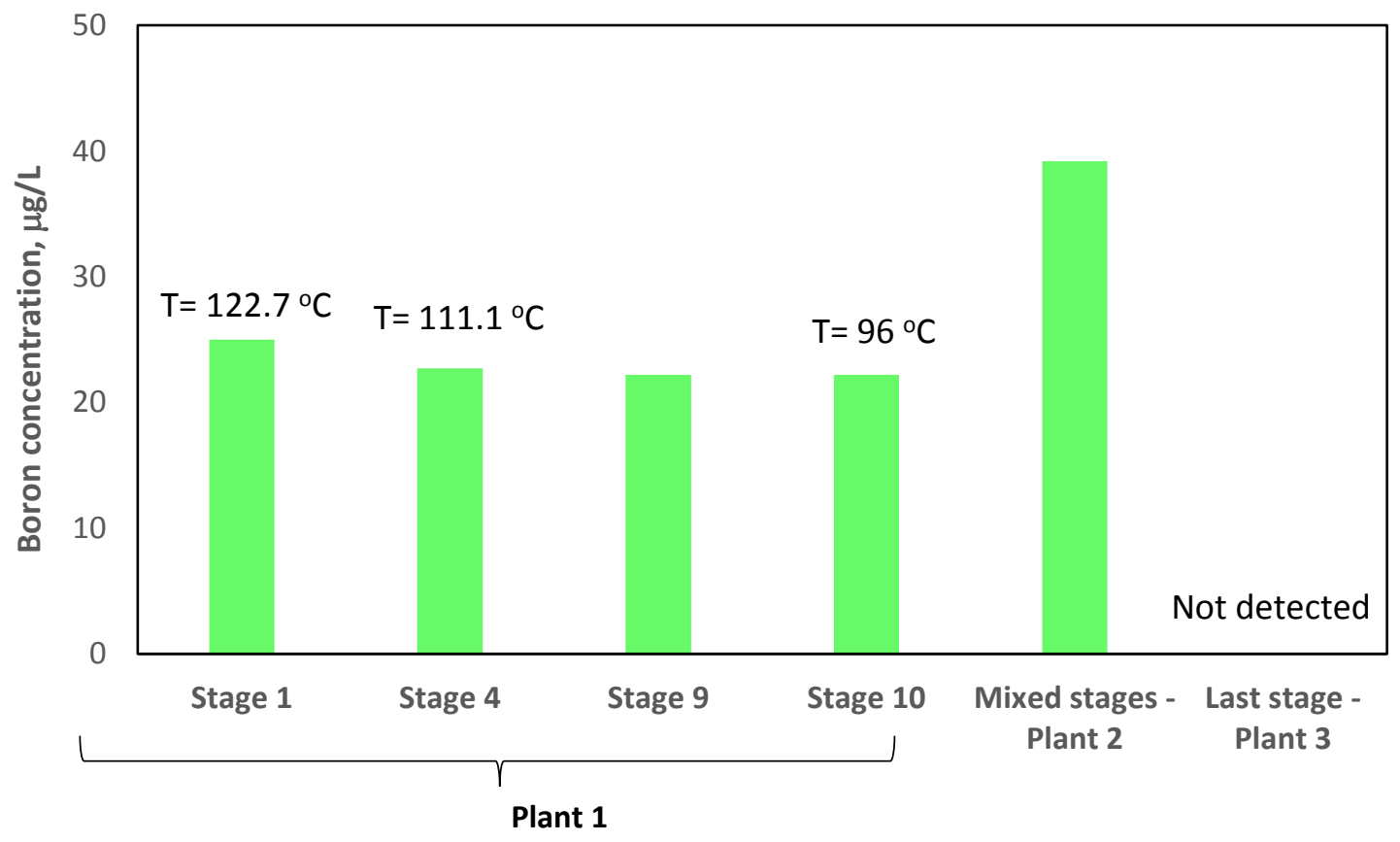

Figure A.2. Boron concentration in distillate samples from commercial MSF plants. 


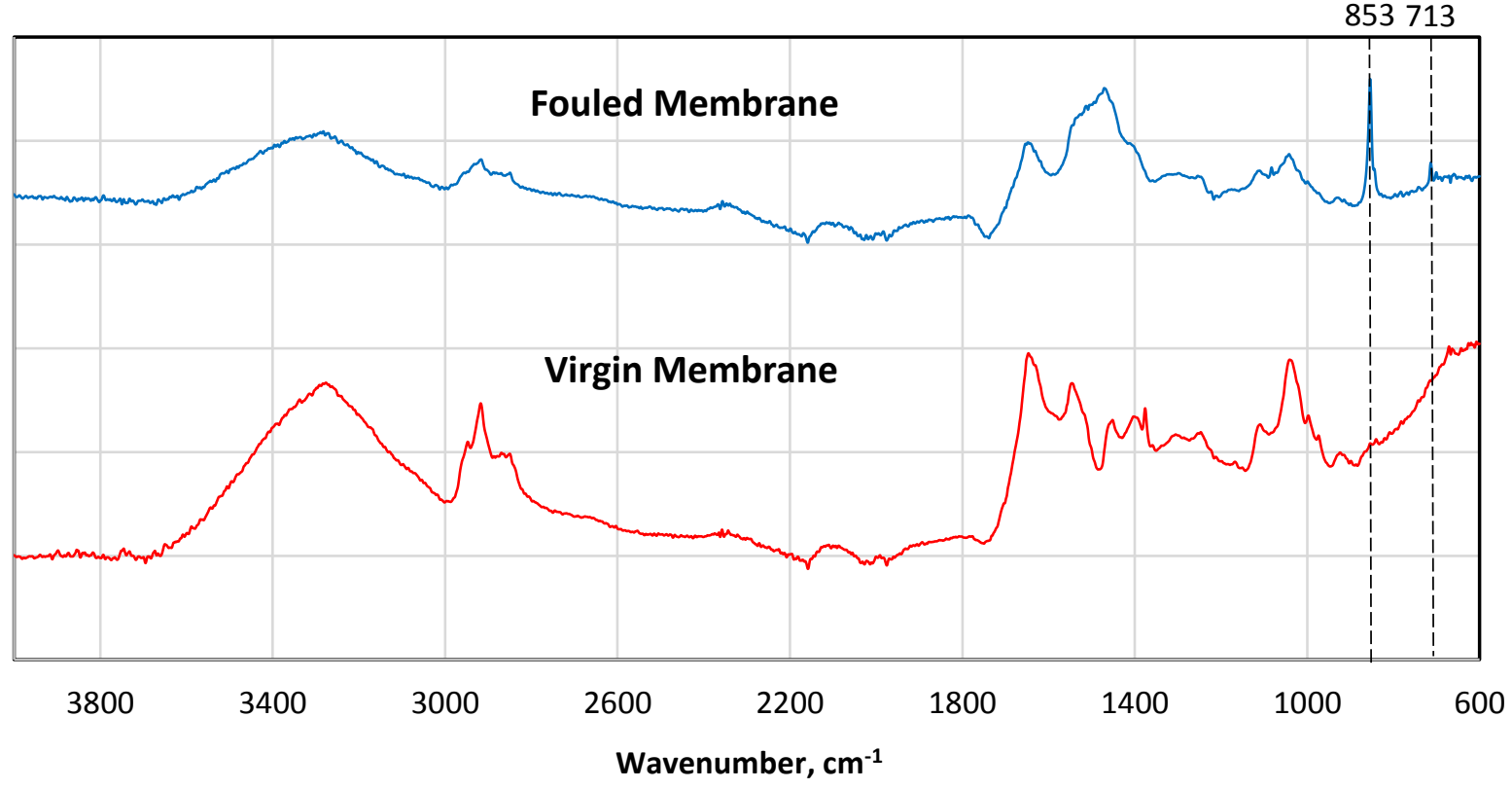

105 Figure A.3. ATR FT-IR spectra of virgin and fouled PVDF membranes after $21 \mathrm{~h}$ of seawater 
122 Table A.1. Calculated molar concentrations and molar fractions of boric acid $\left(\mathrm{H}_{3} \mathrm{BO}_{3}\right)$ and

123 borate ion $\left(\mathrm{H}_{2} \mathrm{BO}_{2}^{-}\right)$in boric acid solution at boron concentration of $5.55 \mathrm{mg} / \mathrm{L}$.

\begin{tabular}{ccccc}
\hline \multirow{2}{*}{$\mathbf{p H}$} & \multicolumn{2}{c}{ Molar concentration, $\mathbf{M}$} & \multicolumn{2}{c}{ Molar fraction } \\
\cline { 2 - 5 } & $\mathbf{H}_{3} \mathbf{B O}_{3}$ & $\mathbf{H}_{2} \mathbf{B O}_{2}^{-}$ & $\mathbf{H}_{2} \mathbf{B O}_{2}^{-}$ & $\mathbf{H}_{3} \mathbf{B O}_{3}$ \\
\hline pH 8.1 & $47.9 \cdot 10^{-5}$ & $3.5 \cdot 10^{-5}$ & 0.07 & 0.93 \\
pH 10.0 & $7.6 \cdot 10^{-5}$ & $43.8 \cdot 10^{-5}$ & 0.85 & 0.15 \\
pH 11.0 & $0.9 \cdot 10^{-5}$ & $51.3 \cdot 10^{-5}$ & 0.98 & 0.02 \\
pH 12.0 & $0.09 \cdot 10^{-5}$ & $51.4 \cdot 10^{-5}$ & 0.998 & 0.002 \\
\hline
\end{tabular}

124

125

126

127

128

129

130

Table A.3. Process parameters and water quality of the distillate samples collected from different commercial MSF plants.

Table A.2. $\mathrm{pH}$ to which the boric acid solution was adjusted at $20{ }^{\circ} \mathrm{C}$ (ambient) and its corresponding value at $104{ }^{\circ} \mathrm{C}$ (in situ). Concentration of boron in boric acid solution was 5.55 $\mathrm{mg} / \mathrm{L}$.

\begin{tabular}{cc}
\hline pH at $20^{\circ} \mathbf{C}$ (ambient) & pH at $104^{\circ} \mathbf{C}($ in situ $)$ \\
8.1 & 7.1 \\
10.0 & 9.0 \\
12.0 & 11.0 \\
\hline
\end{tabular}

\begin{tabular}{|c|c|c|c|c|}
\hline Stage & $\begin{array}{c}\text { Brine temperature, } \\
{ }^{\circ} \mathrm{C}\end{array}$ & $\begin{array}{c}\text { Process pressure, } \\
\mathbf{k P a}\end{array}$ & $\begin{array}{c}\text { Conductivity, } \\
\mu \mathrm{S} / \mathrm{cm}\end{array}$ & Boron, $\mu \mathrm{g} / \mathrm{L}$ \\
\hline \multicolumn{5}{|c|}{ MSF Plant \#1 (Arabian Gulf Coast) } \\
\hline Stage 1 & 122.7 & 1.35 & 11.1 & 24.96 \\
\hline Stage 4 & 111.1 & 0.49 & 14.3 & 22.74 \\
\hline Stage 9 & - & - & 20.8 & 22.15 \\
\hline Stage 10 & 96.0 & 0.18 & 27.2 & 22.19 \\
\hline \multicolumn{5}{|c|}{ MSF Plant \#2 (Red Sea Coast) } \\
\hline $\begin{array}{l}\text { Mixed } \\
\text { stages }\end{array}$ & - & - & - & 39.18 \\
\hline \multicolumn{5}{|c|}{ MSF Plant \#3 (Red Sea Coast) } \\
\hline Last stage & $45-.0$ & - & 5.7 & $\begin{array}{c}\text { Non } \\
\text { detected }\end{array}$ \\
\hline
\end{tabular}


135 Table A.4. Water quality of distillate samples of Red Sea water bench-scale distillation 136 experiments.

\begin{tabular}{ccc}
\hline Temperature, ${ }^{\mathbf{0}} \mathbf{C}$ & $\mathbf{p H}$ & Conductivity, $\boldsymbol{\mu S} / \mathbf{c m}$ \\
\hline 55 & $5.8 \pm 0.1$ & $9.0 \pm 2.1$ \\
65 & $5.8 \pm 0.2$ & $8.0 \pm 2.8$ \\
70 & $5.9 \pm 0.1$ & $11.0 \pm 5.7$ \\
75 & $5.7 \pm 0.1$ & $9.5 \pm 4.9$ \\
80 & $5.9 \pm 0.3$ & $9.7 \pm 1.4$ \\
90 & $5.9 \pm 0.3$ & $8.2 \pm 4.2$ \\
104 & $5.6 \pm 0.1$ & $10.2 \pm 2.1$ \\
\hline
\end{tabular}

138 Table A.5. Quality of Res Sea water permeate collected during the AGMD process at different 139 feed temperatures.

\begin{tabular}{ccc}
\hline Feed temperature, ${ }^{\mathbf{0}} \mathbf{C}$ & $\mathbf{p H}$ & Conductivity, $\boldsymbol{\mu} \mathbf{S} / \mathbf{c m}$ \\
\hline 65.5 & 5.9 & 75.4 \\
70.4 & 5.9 & 55.5 \\
75.5 & 6.0 & 43.3 \\
80.5 & 5.9 & 43.8 \\
\hline
\end{tabular}

140

141 Table A.6. Quality of permeate collected at different times during $21 \mathrm{~h}$ of the AGMD process.

\begin{tabular}{ccc}
\hline Time, $\mathbf{h}$ & $\mathbf{p H}$ & Conductivity, $\boldsymbol{\mu} \mathbf{S} / \mathbf{c m}$ \\
\hline 0 & 5.9 & 135.8 \\
3 & 5.9 & 146.2 \\
5 & 5.8 & 136.3 \\
10 & 6.1 & 262.6 \\
21 & 6.0 & 223.7 \\
\hline
\end{tabular}

142

143 